\title{
A Precision Subsidy Management System for Strawberry Planting in ChangPing District of BeiJing
}

\author{
Zhang Chi, Chen Tian'en, and Chen Liping \\ National Engineering Research Center for Information Technology in Agriculture, \\ Beijing 100097, China \\ zhangc@nercita.org.cn
}

\begin{abstract}
The misuse of pesticide and fertilizer take a great pollution to the agricultural environment, which seriously affects the quality and safety of agricultural products. The government put forward a series of policies of subsidy to lead the farmers to proper pesticide application and scientific farming. But the effect doesn't turn out as it wished to be because of the backward implementation methods and Stat methods. This research provides a Precision Management method for effectively managing subsidies for agriculture. Based on Noncontact IC card, the authors developed a Precision Management System for agricultural related subsidies management. This system was applied in one center and eleven experiment stores in ChangPing district in Beijing and solved problems like poor instruction for planting, tardy in subsidies providing and inaccurate information of stat during the strawberry growing season. Through this system, farmers can get the subsidies and instruction at the moment they buy agricultural materials, government can obtain the accurate data, and then adjustment the policies in time to get the desired effect.
\end{abstract}

Keywords: IC card; subsidy of agricultural materials; precision management; agricultural products safety.

\section{Introduction}

Agricultural pollution has been neglected for a long time due to the high environmental capacity, low level of industrialization, and low population density in rural areas in China. Excessive fertilization, sole-nutrient fertilization and overdose of nitrogenous fertilizer lead to problems like imbalance of soil nutrient, low utilization ratio of fertilization and agricultural environmental pollution. Shoddy fertilizers induce decline of agricultural product quality, even threaten people's life security [1]. According to State Environmental Protection Administration, agricultural pollution occupies as high as 1/3-1/2 of the total amount of nationwide pollution [2]. Thus, scientific farming and reduction of agricultural pollution is the key point to realize agricultural sustainable development strategy.

Local governments has taken many measures to solve this problem, such as grant subsidies to recommended agricultural implements in order to standardize agricultural tools and set up agricultural technical advice station to provide information for scientific farming and rational maturing. These instrumentalities remarkably increase the quality of agricultural products and bring down the agricultural pollution, but there is 
deficiency. Most of the subsidies are released by the end of a year, that is, the allowances are mostly granted after the crop planting period. On the one hand, farmers can not get the subsidies in time; on the other hand, local governments can not get accurate information of requirement of agricultural means of production.

Aiming to solve this problem, this paper provides a precision management method based on non-contract IC card. Assembling government administrative department, agricultural implement agency and farmers together, the authors developed a precision management system based on non-contract IC card to ensure that all the subsidies could be granted in time and that feedbacks could be send back in time. This system was applied in one center and eleven agencies in strawberry planting areas in ChangPing district in Beijing and proved to be efficient.

\section{System Analysis and Design}

\subsection{Requirement Analysis}

Whether information about subsidies of agricultural materials and scientific farming can be conveyed to the farmers precisely will directly affect the agricultural environment and the quality and safety of agricultural products. Meanwhile, the subsidies arriving in time or not will affect farmers' enthusiasm for planting. Based on this, the primary goal of our system is to set up a platform among the government administrative department, agricultural sales departments and farmers in order to pass the information about subsidies of agricultural materials and scientific farming to farmers precisely. Also through this system, providing of subsidies will become more timely and efficient, as a result, farmers' enthusiasm of planting will be enhanced to a great extent.

Our government conducts the subsidies of agricultural materials aiming to ensure the quality of agricultural products and improve agricultural environment. So the subsidies of agricultural materials have to be managed precisely and provided in time so as to ensure the effective implementation of this beneficial policy. For this reason, another function of this system is to provide a tool using which the government can manage the subsidies of agricultural materials precisely. At the same time, by applying this system, related department can achieve a statistical analysis of the information about subsidies of agricultural materials so as to help the government make good policies, and to speed up our agricultural development in the end.

\subsection{System Structure}

To meet the actual requirement, the system consists of six parts such as management subsystem, store subsystem, leader view subsystem, a centre database, several store databases and a huge number of IC card. Due to the different network condition in the agents, the whole system is designed in a telescopic $\mathrm{C} / \mathrm{S}$ structure, through the VPN(virtual private network), each subsystem can connects to each other out of the network condition limited. All agencies submit the sale information to the centre database at a fixed time, consequently, the reliability and stability of the system can be ensured. The leader-view subsystem adopts a B/S structure; leaders can get the realtime information of subsidies anywhere through the browser. Fig 1 is the structure of Precision Management System for the subsidy of agricultural materials. 


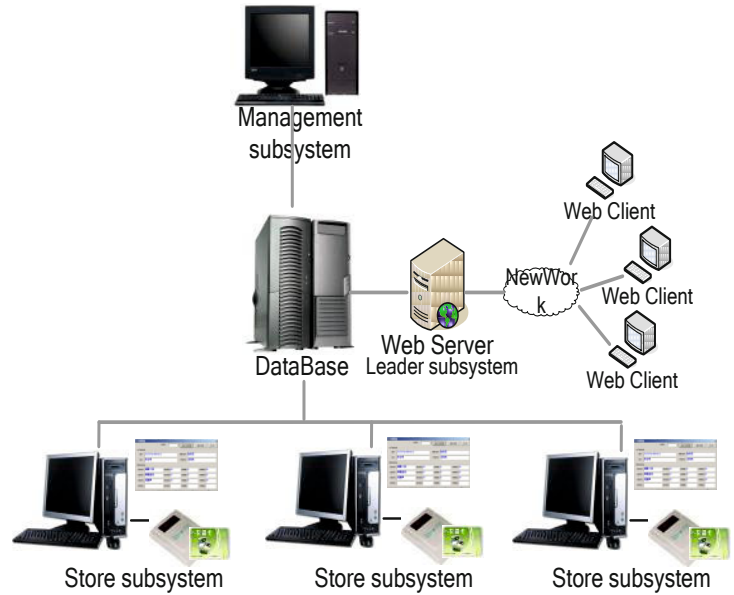

Fig. 1. The structure of Precision Management System for the subsidy of agricultural materials

\subsection{The Major Business Process}

According to the procedure of strawberry production in ChangPing distinct, the management subsystem inputs the first batch of data based on the land distributiton data and the details of subsidy. Adopt the mechanism 'one farmer one card', each farmer gets a IC card with his name, account, quota of subsidy, permit time and the printed growing instructions. In accordance with the latest information of subsidy download from the management subsystem, the payment for agricultural materials is made up of two parts, the one is cash part, paid by farmers, the other is subsidy, deducted from

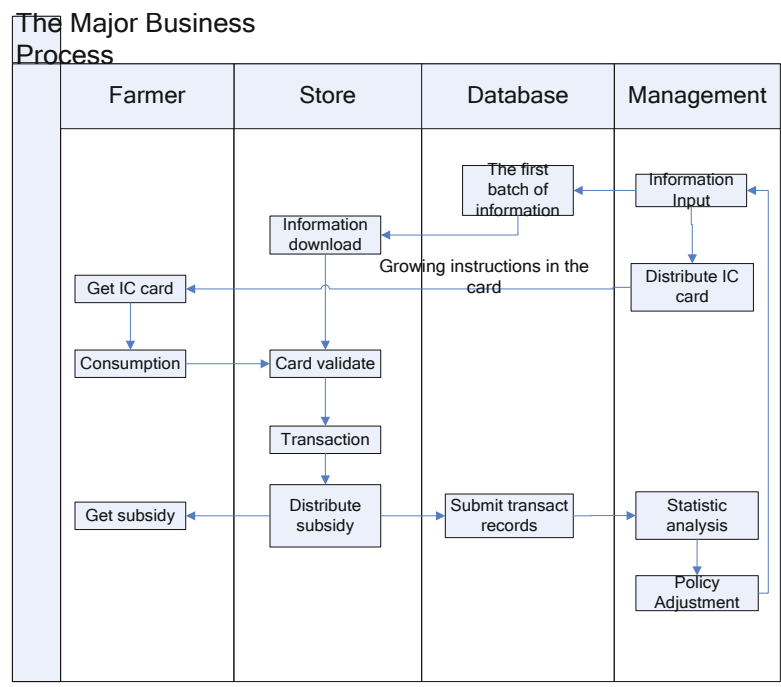

Fig. 2. The major business process of Precision Management System for the subsidy of agricultural materials 
the IC card. Stores take a record of each transaction, and submit the records to management subsystem in a fix time. The management subsystem achieves a statistical analysis of the distribution process and using circumstances about subsidies of agricultural materials through these records. Based on the results of the statistics, government can adjust subsidy policy in time and then play a better role in guiding. Fig 2 is the major business process of Precision Management System for the subsidy of agricultural materials.

\subsection{The Key Technology}

\subsubsection{Real-Time Performance of the System}

The major problems to be solved in the system are how to distribute subsidy in time and accurate statistics the data of subsidy. IC card of non-contact type (M1) is used, the farmer's name, account, balance, subsidy freeze, distribute date, commencement date, check date, ending date, card status and growing instructions are stored in the sectors of IC card. When farmer buy the agricultural materials, store subsystem calculates the total price and the subsidy should be distributed, subsidy bill is deducted from IC card, the balance is paid in cash. Store subsystem save the details such as account, name, price, number, cash, subsidy, serial and assistant into store database with status " 0 " when each transaction is finished. Store subsystem checks the records periodically, while finding records with status " 0 ", immediately submits these records to management subsystem and updates the status with " 1 ". Though this, the subsidy can be distributed in time and data of subsidy can be accurate statistics.

\subsubsection{System Security}

The whole system is a distributed system. In the server aspect, adopts the dual module hot spare(DMHS), if one server is crash down, System can switches to another server automatically in two minutes, which guarantees the security of database. In the data interaction aspect, set up a virtual private network, each subsystem has a multiple verification mechanism and all data is delivered unidirectional, which ensure the security of the data.

\section{System Implementation}

\subsection{Management Subsystem}

Considering the factors of development efficiency, interface effects and user demand, we used Visual C \# as the development language, under the Visual Studio 2005 environment, combined with ESRI's ArcGIS Engine 9.3 SDK for system development. After comprehensive consideration of the data security, operating efficiency and system extension, chose SQL Server 2005 as the data base.

Management sub-system was comprised of three function modules including the IC card management module, information maintenance module and data query statistics module. It is precisely the information publish and integrate centre of the precision management system for the subsidy of agricultural material, which provides IC card and growing instructions for farmers, recommended agricultural materials and subsidy information for agencies, accurate statistical data of subsidies for the government departments. Fig 3 shows the card distribution interface of management sub-system. 


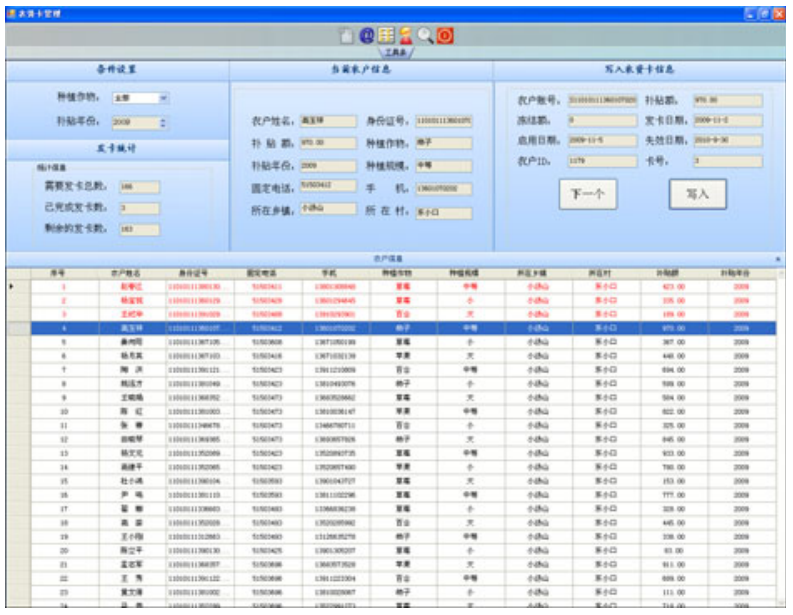

Fig. 3. Sending card page of the management subsystem

\subsection{Store Subsystem}

As a bridge between the government and farmer, the store subsystem complete the whole transaction processes. The distribute store subsystem acquires the information of the recommended agricultural materials and related subsidies information from the management subsystem and then transmit to the farmer. Store subsystem distributes subsidies to farmers as soon as they buy the agricultural materials with agricultural subsidies IC card, and then saves the detailed information for each transaction. Every store uploads the transaction data to the central database periodically to summary, aiming to query and stat. Fig 4 is the sale page of store subsystem.

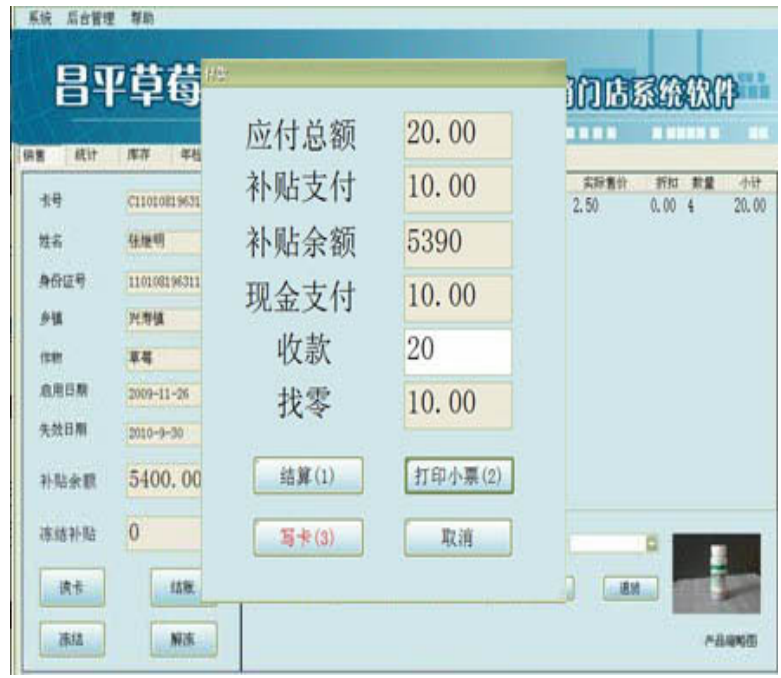

Fig. 4. Sale page of store subsystem 


\subsection{Leader View Subsystem}

Leader view subsystem provides a rich query and statistical functions. User can query the grant general progress of agricultural subsidies with the conditions of area, kind and time, the detailed circumstances of agricultural subsidies granting and agricultural products using the conditions of town, month / quarter and agricultural materials' name. All results are compared in different dimensions and displayed in graphs and tables. Analyzing these results, the management department of government can know the farmers' demand and subsidies grant progress roundly. Fig 5 is the statistics page of the leader subsystem.

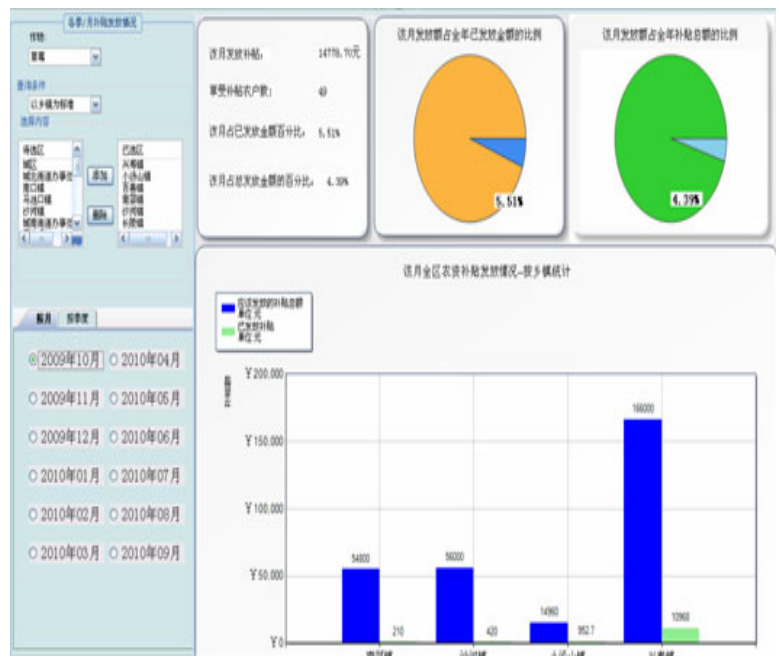

Fig. 5. Subsidy statistics by month page of the leader subsystem

\section{The Practical Application}

Finishing the development work of the precision management system, it takes the agricultural materials management department of ChangPing district in BeiJing as the center, set up eleven experiment agencies in the towns like Xingshou, Xiaotangshan, Baishan, Shahe, Machikou, Cuicun, Five thousands farmers are benefited for it. the system adopts the mechanism of ' one farmer one card ' to realize unified management on agricultural materials' recommendation, purchase, sale and subsidies of the whole district, making a connection between sale and subsidy of the agricultural materials, realizing the accurately recording of sale information, the real-time summarizing of the subsidy data and the timely distribution of subsidy, integrating the resource of strawberry grow effectively, mobilizing the energies of farmers and Guaranteeing the quality of agricultural product at the same time, laying the foundations of the development of strawberry industry in ChangPing district. 


\section{Conclusion}

To meet the needs of precision management of granting subsidies during strawberry planting, this paper designed and developed a precise managerial system of subsidies supervision. Employing modern communication technology, this system built an information alternation platform among government administrative department, agricultural implement agency and ordinary farmers. Based on non-contract IC card, this precise system of subsidies supervision could send the statistic feedback in time; the farmers could promptly receive the subsidies and get guidance of scientific planting from the government. As a management system controlling the inception of agricultural material investigation, this project achieved the traceability of agricultural material during strawberry planting; reduced pollution caused by absurdness fertilizer application and consequently ensured the quality of agricultural production.

\section{Acknowledgements}

We wish to thank the students of National Engineering Research Center for Information Technology in Agriculture who took part in the field data collection, and Dr.Chen Tian-En for his comments on an earlier version of the manuscript. The National Technology Support Project, Project no. 2008BADA4B03 and The 863 Plans Projects, Project no. 2010AA10A301 are gratefully acknowledged for the support of our research.

\section{References}

[1] Li, B., Tan, C., He, R.: Prevention and Control of Fertilizer Pollution on Environment. Science and Technology of Modern Agriculture (4), 193-195 (2009)

[2] Guo, Y., Zhang, C., Zhang, L.: On Agricultural Pollution in China. Journal of Anhui. Agri. Sci. 37(4), 1773-1775 (2009)

[3] Tian, Y., Jin, O.: Desiging and Implementation of GPRS Network Vending Machine Based on IC Card Payed. Computer Knowledge and Technology 6(7), 1755-1757 (2010)

[4] Zheng, J., Zhou, H., Xu, Y., Maocheng: Toward-target precision pesticide application and its system design. Transactions of the CSAE 21(11) (2005)

[5] Zhang, H., Zheng, J., Zhou, H., et al.: Key technologies fir integration of information flow for precision pesticide application system. Transactions of the CSAE 23(5), 130-136 (2007)

[6] Zhou, Z., Cao, W., Zhu, Y., Wang, S., et al.: GIS-based information system for crop production management. Transactions of the CSAE 21(1), 114-118 (2005)

[7] Li, H., Shi, A.: Design and Implementation of an Automobile Exhaust Emission Inspecting Data Management Information System Based on IC Cards. Computer Engineering \& Science 32(1), 156-158 (2010)

[8] Ren, M., Zhang, X., Zhang, J., Wang, Z., et al.: Development of web-based Chinese tobacco germplasm resources information system. Transactions of the CSAE 26(3), 209-215 (2010)

[9] Ji, Z., Sun, C., Qian, J., et al.: Pig healthy breeding information management system based on.NET. Transactions of the CSAE 24(supp. 2), 230-234 (2008) 